\title{
The Role of Molecular Typing for DQ2 and DQ8 Alleles Using Polymerase Chain Reaction Amplification in Children with Autoimmune Conditions
}

\author{
OANA BELEI ${ }^{1}$, ANDREEA DOBRESCU ${ }^{2}$, EMIL RADU IACOB ${ }^{3 *}$, DANIELA IACOB ${ }^{*}$, \\ ELENA AMARICAI ${ }^{5}$, OTILIA MARGINEAN ${ }^{1}$ \\ ${ }^{1}$ Victor Babes University of Medicine and Pharmacy Timisoara, First Pediatric Clinic, 2 Eftimie Murgu Sq., 300041, \\ Timisoara, Romania \\ ${ }^{2}$ Victor Babes University of Medicine and Pharmacy Timisoara, Genetics Department, 2 Eftimie Murgu Sq., 300041, \\ Timisoara, Romania \\ ${ }^{3}$ Victor Babes University of Medicine and Pharmacy Timisoara, Pediatric Surgery Department, 2 Eftimie Murgu Sq., \\ 300041, Timisoara, Romania \\ ${ }^{4}$ Victor Babes University of Medicine and Pharmacy Timisoara, Neonatology Department, 2 Eftimie Murgu Sq., 300041, \\ Timisoara, Romania \\ ${ }^{5}$ Victor Babes University of Medicine and Pharmacy Timisoara, Department of Rehabilitation, Physical Medicine and \\ Rheumatology, 2 Eftimie Murgu Sq., 300041, Timisoara, Romania
}

\begin{abstract}
The aim was to determine the prevalence of celiac disease (CD) in a pediatric population with juvenile idiopathic arthritis (JIA) and autoimmune hepatitis (AIH) compared to controls and to evaluate the clinical forms and human leukocyte antigen (HLA) alelles. Between September 2009November 2019, 74 pediatric patients with JIA (1), 62 AIH (2) and 60 controls were assessed for CD. All children with one or more positive CD antibodies were submitted to gastrointestinal endoscopy with intestinal biopsy. All patients underwent HLA molecular assessment for DQ2/DQ8 alleles. Celiac prevalence after screening was $6.7 \%$ in the first group, $6.4 \%$ in the second group and $0 \%$ among controls. The results didn't reveal significant differences regarding the CD prevalence among patients with JIA and AIH $(p=0.94)$. The majority of cases associated the silent form of disease (77.7). $D Q 2 / D Q 8$ haplotypes were found in all CD cases. Of 69 children with JIA and no CD, three (4.3\%) had DQ2 haplotype. Of 58 patients with AIH and no CD, 37 children (63.8\%) presented DQ2/DQ8. According to the high prevalence obtained in this study, JIA and AIH are good parameters for stratification of asymptomatic cases in order to perform $C D$ serologic screening. The absence of $D Q 2$ or DQ8 haplotypes will make CD diagnosis unlikely and no further tests will be required.
\end{abstract}

Keywords: children, juvenile idiopathic arthritis, autoimmune hepatitis, celiac disease

\section{Introduction}

Gluten enteropathy, synonymous with celiac disease (CD), is an autoimmune condition that underlies a malabsorption syndrome in about $1 \%$ of the population [1]. Due to the increase in gluten consumption and the widespread diagnosis of asymptomatic forms of celiac disease with increasing accuracy of diagnostic tests, CD incidence has increased in the last decade [2]. Still, the iceberg model described by many authors demonstrates the percentage of undiagnosed forms of CD in the general population [3].

Current research has shown that the classical CD definition is restricted to $30 \%$ of all subjects with genetic susceptibility and characteristic intestinal histological lesions, omitting most cases with gluten enteropathy that associate minimal villous alterations [4]. Most forms of CD are outside the context of the classical definition, being pauci-symptomatic, atypical or silent.

Currently, CD is depicted as an autoimmune enteropathy induced by gluten exposure in subjects with genetic susceptibility translated by the association of the human leukocyte antigen (HLA) DQ2/DQ8.

\footnotetext{
*email: radueiacob@umft.ro; danielariacob@yahoo.com
} 
This condition can present digestive or extra-digestive manifestations but can associate an asymptomatic form in patients with susceptible genetic backgrounds that have certain autoimmune conditions or genetic diseases [5].

Currently, the strategy of serological testing for CD of all subjects with risk factors is considered cost-effective, thus increasing the rate of diagnosis of atypical, asymptomatic or silent forms of the disease.

Recent research has published different percentages of the association of autoimmune comorbidities among CD subjects. As the period of gluten exposure increases, so does the prevalence of these conditions among patients with gluten enteropathy [6]. Among CD patients the prevalence of insulin-dependent type I diabetes (IDDM) is $2.3 \%-11 \%$ [7], the prevalence of autoimmune thyroid disorders (AITD) is $13 \%$ [8], the prevalence of juvenile idiopathic arthritis (JIA) is $1.5 \%-7.5 \%$ [9], the prevalence of autoimmune hepatitis (AIH) is $12.5 \%$ [10], the prevalence of Sjögren's syndrome is $2 \%$ $15 \%$ [11], the prevalence of IgA selective deficiency is $2 \%-4.8 \%$ [12] and the prevalence of dermatitis Duhring-Brocq is $20 \%-25 \%$ [13].

The objective of this research was to establish the prevalence of gluten enteropathy among children from the west part of the country diagnosed with JIA and AIH compared to a control group. The second aim was to assess the stratification of clinical forms of the disease correlated with HLA allele polymorphism.

\section{Materials and methods}

In this prospective observational study, the authors performed a general screening by serologic testing for gluten enteropathy to all consecutive pediatric patients admitted to Pediatric Gastroenterology and Pediatric Rheumatology Departments of our hospital with JIA and AIH from September 2009 to November 2019 and in all subjects from the control group. All legal tutors of children participating to the study have signed a written informed consent.

74 consecutive children diagnosed with JIA according to the International League of Rheumatism criteria [14], were screened for CD. This was the first lot of study.

Diagnosis of JIA was based on the history and physical examination findings (arthritis, synovitis) along with imagistic (radiography, magnetic resonance or computed tomography) and laboratory investigations (inflammatory markers, rheumatoid factor, antinuclear antibodies, anti-cyclic citrullinated peptide antibody). Children with the following types of JIA were referred to celiac screening: systemic-onset JIA, oligoarticular JIA, polyarticular JIA, psoriatic arthritis, enthesitisrelated arthritis, or undifferentiated arthritis.

62 consecutive children with AIH underwent serological screening for CD. This was the second lot of study. AIH was diagnosed in all children following the grading system of the International Autoimmune Hepatitis Group Score [15] and specific pathological findings in liver biopsy. AIH was diagnosed by increased IgG serum level, positive specific auto-antibodies and interface hepatitis morphologic features.

AIH has two main types. Type 1 is frequently diagnosed in adult patients, being characterized by positive anti-smooth muscle and anti-nuclear antibodies. Type 2 presents antibodies against liver cytosol type 1 antigen and anti liver-kidney microsome type 1 antibodies [16]. The second lot included 17 patients with type 1 and 45 cases with type $2 \mathrm{AIH}$.

There were 60 children in full health condition enrolled in the control lot. There weren't any autoimmune, rheumatologic or gastrointestinal conditions in the medical history of controls.

The authors performed serologic screening for CD to all patients with JIA/AIH and to all subjects from the control lot assessing IgA and IgG antibodies against deamidated gliadin (DGP), tissuetransglutaminase (TTG) and anti-endomysium (EMA).

All patients with one or more positive serologic result enrolled in the first and the second lot were submitted to upper digestive endoscopy and intestinal biopsy. Two biopsies were taken from the duodenal bulb and four biopsies from the second portion of the duodenum in each child. The 
histological classification of the biopsies was done according to the Marsh criteria modified by Oberhuber [17].

The classification of villous lesions was done as follows: Marsh 0 - normal intestinal histological appearance, Marsh 1- presence of lymphocytic infiltrate in chorion, Marsh 2- hyperplasia of glandular crypts with lymphocytic infiltrate, Marsh 3 - villous atrophy (partial Marsh 3A, subtotal Marsh 3B or total Marsh 3C) [17].

All children including the controls underwent HLA typing for DQ2 and DQ8 alleles assessment. The QIAamp DNA Blood Mini kit (Qiagen N.V.) was used to extract deoxyribonucleic acid (DNA), given an optimal concentration of $50 \mathrm{ng} / \mu \mathrm{l}$ DNA to initiate an efficient polymerase chain reaction (PCR) amplification.

The following kits were used for genomic testing: All Set Gold HLA DQB1 02/04, All Set Gold HLA DQA1 and All Set Gold HLA DQB1 03, Dynal-Invitrogen (Life Technologies Ltd, Scotland, UK). The extracted genomic DNA was assessed using specific primers (PCR-SSP) in order to investigate the presence of DQ2 and DQ8 haplotypes. The quantification of the results was based on the Worksheet-Gel Documentation Form attached to the test kit which includes all the allele combinations that can be obtained.

60 children (81\%) diagnosed with JIA received disease-modifying anti-rheumatic drugs. The most frequently administered drug was methotrexate $\left(\mathrm{C}_{20} \mathrm{H}_{22} \mathrm{~N}_{8} \mathrm{O}_{5}\right)$ (Figure 1). 14 children (19\%) required biologic therapy based on tumor necrosis factor inhibitors - etanercept.

Methotrexate $\left(\mathrm{C}_{20} \mathrm{H}_{22} \mathrm{~N}_{8} \mathrm{O}_{5}\right)$ suppress the host immunity_by inhibition of dihydrofolate reductase enzyme and by down regulation of $\mathrm{B}$ and $\mathrm{T}$ lymphocytes activity.<smiles>CN(Cc1cnc2nc(N)nc(N)c2n1)c1ccc(C(=O)N[C@@H](CCC(=O)O)C(=O)O)cc1</smiles>

Figure 1. Methotrexate chemical formula

Tumor necrosis factor-alpha $(\mathrm{TNF} \alpha)$, a proinflammatory cytokine synthetized by lymphocytes, is an important immune mediator. It initiates and maintains the inflammation. Etanercept inhibits TNF $\alpha$, down-regulating the inflammatory function. The etanercept molecule has a complex structure containing 6 Nglycans, 14 Oglycans and 29 disulfide bridges. Its chemical formula is $\mathrm{C}_{2224} \mathrm{H}_{3475} \mathrm{~N}_{621} \mathrm{O}_{698} \mathrm{~S}_{36}$.

All the children diagnosed with AIH initially received steroids (prednisone). After tapering the prednisone dose, azathioprine was added in order to maintain the immune suppression and to avoid steroids side effects in children. Prednisone is a glucocorticoid drug administered in order to suppress the host immunity and to decrease the inflammatory response in the majority of autoimmune conditions. Its chemical formula is $\mathrm{C}_{21} \mathrm{H}_{26} \mathrm{O}_{5}$ (Figure 2).

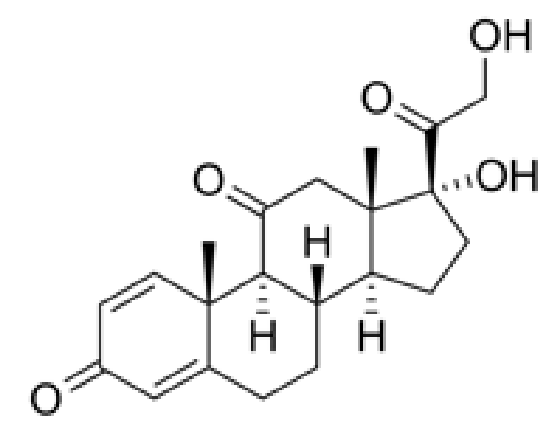

Figure 2. Prednisone chemical formula 
Azathioprine is another immunosuppressive drug. Azathioprine is an inactive prodrug that will be activated by conversion in 6-mercaptopurine. Its action is based on purine synthesis inhibition. Azathioprine chemical formula is $\mathrm{C}_{9} \mathrm{H}_{7} \mathrm{~N}_{7} \mathrm{O}_{2} \mathrm{~S}$ (Figure 3).<smiles>Cn1cnc([N+](=O)[O-])c1Sc1ncnc2nc[nH]c12</smiles>

Figure 3.

Azathioprine chemical formula

In this study, the authors used R 3.2.3 statistical software (Free Software Foundation's GNU project) for data analyze.

\section{Results and discussions}

Between September 2009 and November 2019, 74 children with JIA - constituting the first study group, 62 children with AIH - constituting the second group and 60 healthy control subjects were analyzed serologically for the detection of gluten enteropathy.

Following the serological screening, five CD patients were detected in the first lot of study. Four of these patients with gluten enteropathy showed altered intestinal morphology, and one child had normal villous architecture, being framed in the form of latent disease. The latter patient had genetically susceptible background (heterozygous DQ2 HLA) and positive serological tests for celiac disease (IgA / IgG TTG / DGP and EMA).

The prevalence of gluten enteropathy in the first study group including the case with the latent form of the disease was $6.7 \%$.

The first study group presented the following stratification of CD forms: a case with typical form of the disease associating chronic diarrhea, failure to thrive, positive serologic tests and total villous atrophy (Marsh 3C), 3 cases with silent forms of disease - asymptomatic, but with positive serology and characteristic intestinal lesions and a latent form of disease.

The flow chart of CD children recruitment from the first lot of study is shown in Figure 4.

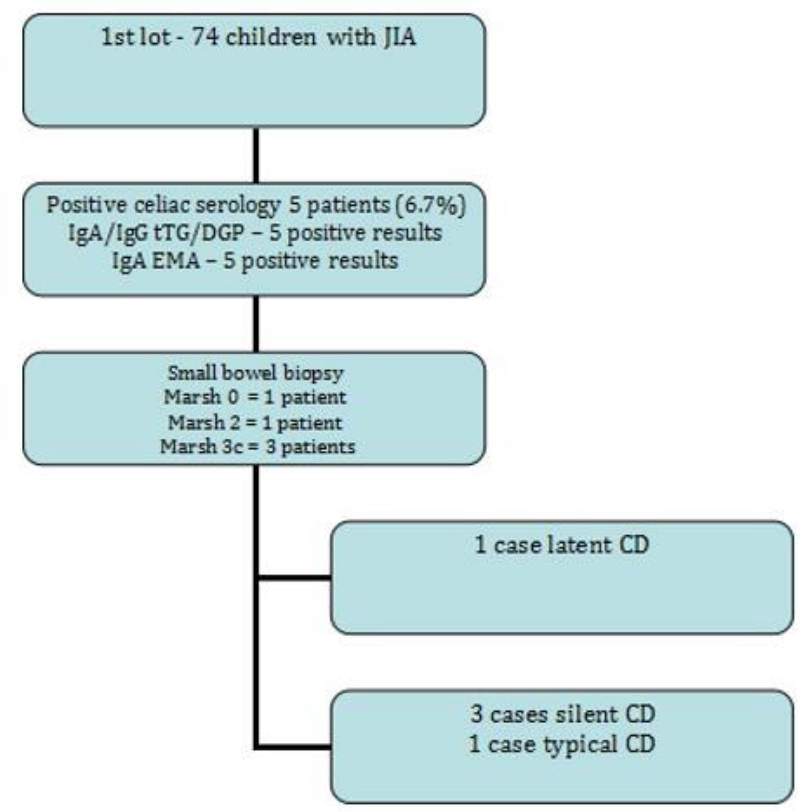

Figure 4. Flow chart of JIA/CD patients' recruitment 
Of the 62 patients with $\mathrm{AIH}$, four were diagnosed with gluten enteropathy based on the serological and histological characteristic criteria presented above. The prevalence of gluten enteropathy in the second study group was $6.4 \%$. All cases associated the silent form of disease.

The flow chart of CD children recruitment from the second lot is presented in Figure 5.

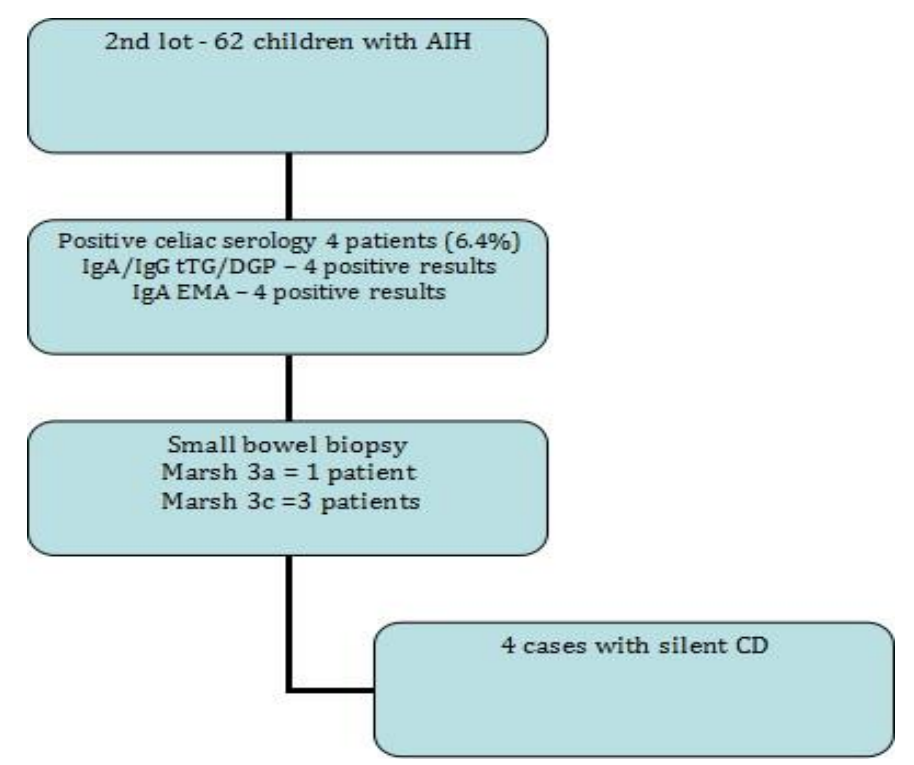

Figure 5. Flow chart of AIH/CD patients recruitment

The authors didn't find any positive serological result for gluten enteropathy among controls, therefore $\mathrm{CD}$ prevalence in the control lot was $0 \%$.

We compared CD prevalence in the first lot of study with JIA $(6.7 \%)$ with the rate of gluten enteropathy in the second lot of study with $\mathrm{AIH}(6.4 \%)$. We didn't find a statistical significant difference $\mathrm{p}=0.94$, CI:[-0.08 to 0.086].

The combined analysis of all children diagnosed with CD and comorbidities showed that the majority of cases presented the silent form of disease. Of nine patients diagnosed with CD (6 females and 3 males, mean age 5.2 \pm 1.2 years, range $1-18$ years), 7 patients $(77.7 \%)$ had silent form of CD.

The authors assessed DQ2/DQ8-HLA by molecular typing to all subjects enrolled in this study. All five patients diagnosed with gluten enteropathy from the first study lot had heterozygous DQ2 alleles. From the remaining 69 patients without gluten enteropathy, only three (4.3\%) had heterozygous DQ2 HLA and the others (95.6\%) associated different HLA haplotypes, non DQ2/DQ8.

The distribution of HLA-DQ alleles in the first lot of study is shown in Figure 6.

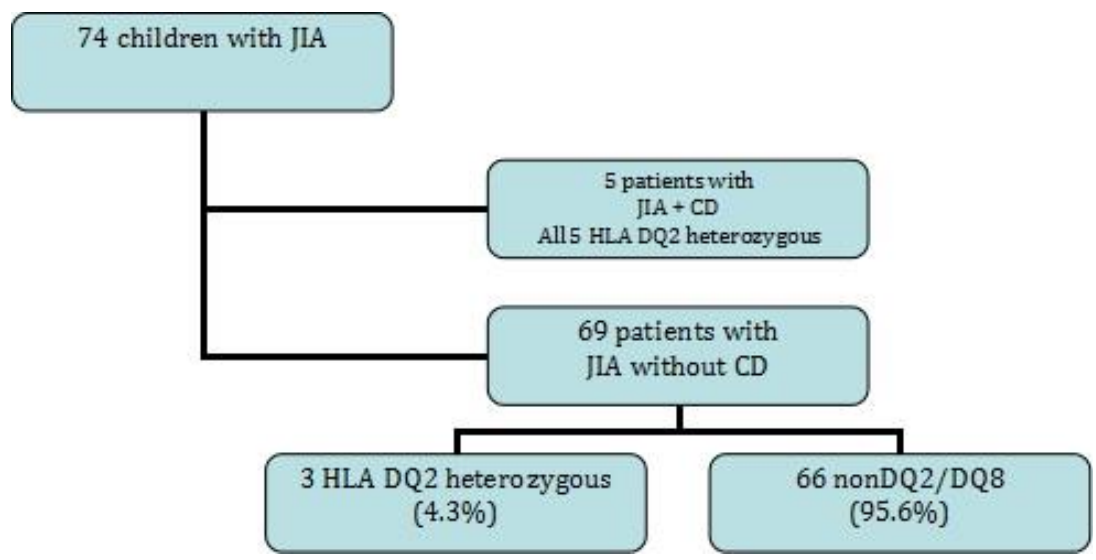

Figure 6. Distribution of HLA DQ alleles in patients from the first lot with JIA 
Of the four children diagnosed with $\mathrm{CD}$ after screening from the second group, one case associated DQ8 alleles, two patients had heterozygous DQ2 haplotypes and one child had homozygous DQ2 haplotype.

The distribution of HLA-DQ alleles in the second lot of study is shown in Figure 7.

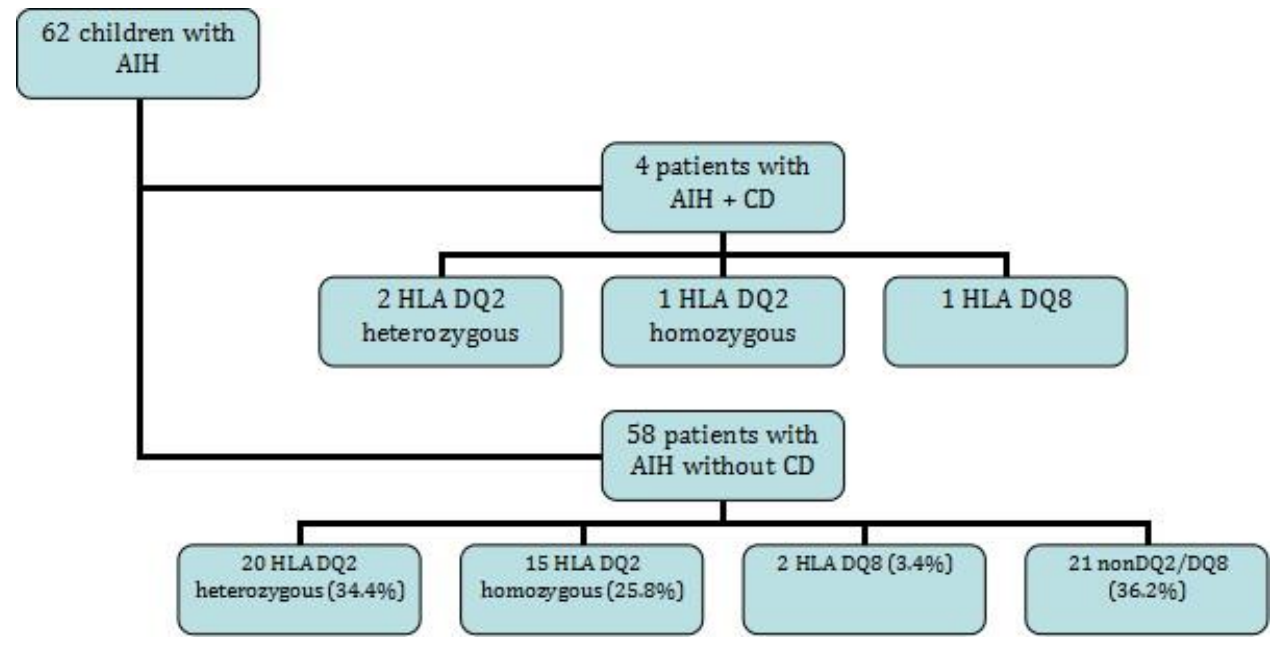

Figure 7. Distribution of HLA DQ alleles in patients from the second lot with AIH

In the control group, 12 subjects $(20 \%)$ had predisposing genetic background for CD (heterozygous DQ2) and the remaining presented different non - DQ2/DQ8 haplotypes.

The alleles distribution in each lot of study is depicted in Figure 8.

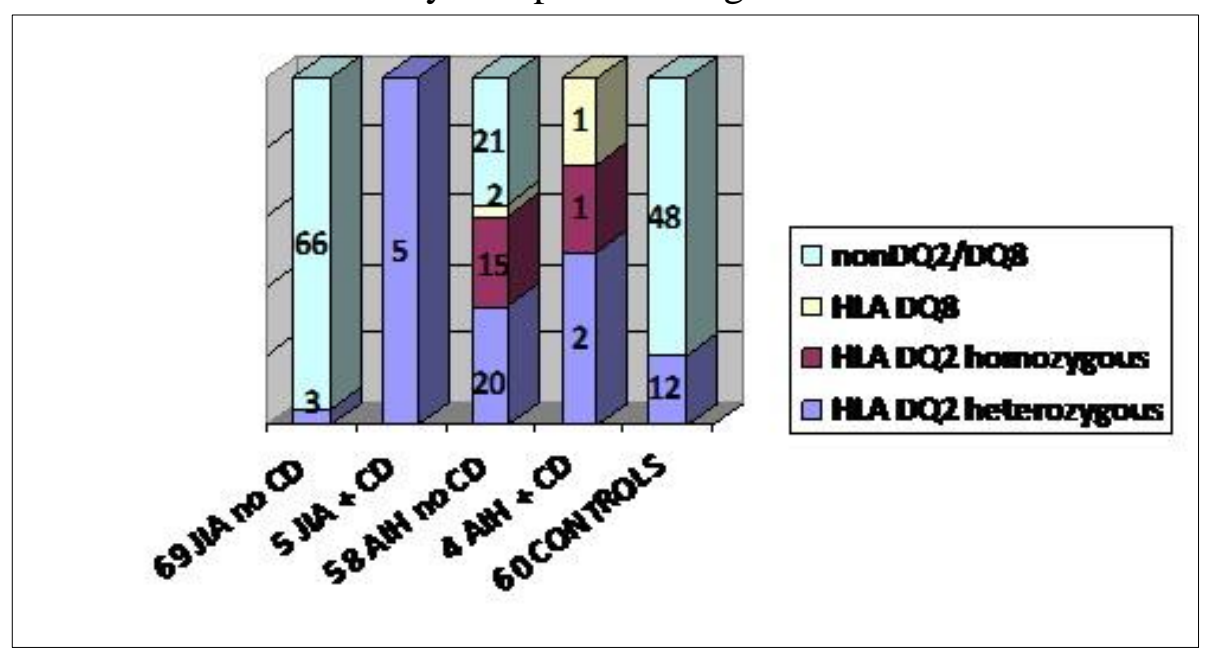

Figure 8. Alleles distribution in each lot of study

The majority of children with negative serologic results for gluten enteropathy presented non DQ2/DQ8 alleles.

Of 74 children with JIA that underwent serological screening, CD was diagnosed in five subjects $(6.7 \%)$, a similar percent compared to other publications. CD prevalence varied between $2.5 \%$ and $6.5 \%$ among JIA children according to several older studies [18-21]. The most frequent JIA forms that have been diagnosed as a comorbidity with gluten enteropathy were oligo-articular and polyarticular $[18,22]$ and only few celiac children had systemic-onset JIA $[18,23]$.

Increased prevalence of CD among patients with JIA compared to general population has been published [18-22, 24]. 
These comorbidities can disrupt normal growth and development, and subsequently fertility. Consequently, early diagnosis is essential to prevent complications, especially in pediatric patients. The association of these two autoimmune diseases CD and JIA can be explained by a particular genetic predisposition [25].

It is interesting to note that $\mathrm{CD}$ may remain asymptomatic for several years but is associated with a high risk of the second autoimmune condition [18].

Alpigiani reported cases of gluten enteropathy diagnosed in patients with JIA 3.5 and 4.6 years after the onset of joint disease [20].

A lot of publication assessed the coexistence of CD with AIH. Our study indicated a high rate (6.4\%) of biopsy- confirmed gluten enteropathy among AIH children. Similar results were reported by other investigators. A recent Iranian study [10] found that the rate of gluten enteropathy in a pediatric population with AIH was higher compared to general population $(4.7 \%)$. On the other hand, vice versa, the same study showed a higher prevalence of AIH (12.5\%) than previously reported in celiac patients. An older study found in a large group of children with $\mathrm{CD}$, a prevalence of only $1.1 \%$ for AIH [26]. The explanation of these different results consists in the fact that the Iranian study included seronegative patients with liver biopsy-confirmed autoimmune hepatitis. These patients were considered as having cryptogenic autoimmune hepatitis and the evaluation of anti-soluble liver antigen (SLA) was helpful [10]. Another recent meta-analyze published by Wong [27] found the copresentation of $\mathrm{AIH}$ with $\mathrm{CD}$ as being clinically important, with a prevalence up to $6 \%$, similar to our results.

The genetic predisposition for gluten enteropathy is defined by the presence of DQ2 and DQ8 HLA. HLA-DQ2 heterodimer consists in DQA $1 * 0501$ and DQB*0201 alleles arranged in cis form by DR3-DQ2 haplotype or DQA1*0505 and DQB *0202 alleles arranged in trans conformation by DR5DQ7/DR7-DQ2 haplotype. HLA-DQ8 heterodimer consists in DQA1*0301 and DQB1*0302 alleles arranged in cis form by DR4-DQ8 haplotype [28].

An important step in the screening of asymptomatic subjects that associate risk factors for CD is the haplotype analysis [29].

The analysis of the haplotype has a special value in CD diagnostic algorithm by excluding the condition in subjects with positive serological tests but normal villous morphology [29]. HLA DQ2 and DQ8 have a negative predictive value of $100 \%$, allowing CD exclusion in uncertain cases. Also, many studies support the importance of analyzing DQ2 and DQ8 haplotypes in subjects with high suspicion of $\mathrm{CD}$ associated with other autoimmune disorders. The common predisposing genetic background underlies the possible autoimmune comorbidities in patients with gluten enteropathy [30].

In this research, the authors also analyzed the association of genetic predisposition for CD in nonceliac patients. In the lot of JIA patients, the analyze was focused on DQ2 and DQ8 alleles and not on HLA B27. There were only three patients $(4.3 \%)$ with predisposing haplotype for CD (DQ2 HLA) among the 69 children with JIA without CD. On the contrary, from a total of 58 patients with AIH without $\mathrm{CD}$, more than half (37 children-63.8\%) presented the predisposing genetic background for gluten enteropathy (DQ2 or DQ8 haplotype) in the absence of the disease, $\mathrm{p}<0.001, \mathrm{CI}:[-0.727$ to $0.461]$.

The high percentage of cases with AIH and allelic conformation characteristic for gluten enteropathy, which did not associate $\mathrm{CD}$, is explained by a greater genetic similarity between AIH and $\mathrm{CD}$, compared to the relationship between gluten enteropathy and JIA. However, the authors of this study did not find statistically significant differences between the number of cases with gluten enteropathy diagnosed in the two study groups: $6.7 \%$ and $6.4 \%$ respectively, $p=0.94, \mathrm{CI}$ : [- 0.08 to 0.086].

AIH and gluten enteropathy are based on a common predisposing genetic field (genes belonging to HLA class two), which explains their association at the same subject. Increased intestinal permeability and the spread of anti-tissue transglutaminase antibodies that can damage the liver in patients with gluten enteropathy are also involved in this comorbidity [31]. 
In patients diagnosed with JIA, the risk factors underlying the possible association of gluten enteropathy are represented by certain genes of the HLA complex on chromosome 6 , but also other non-HLA regions $[32,33]$.

Our results regarding HLA distribution are in agreement with other published data, emphasizing that the presence of HLA DQ2 or DQ8 alleles is mandatory, but not enough for the disease to become symptomatic. In our study $20 \%$ of the controls associated predisposing genetic background for CD without developing the disease.

Gluten enteropathy is a multigenic condition, but HLA DQ2 or DQ8 alleles are crucial for the development of the disease. These haplotypes are mandatory, but insufficient to cause the disease without another factors intervention. Thereby DQ2 and DQ8 haplotypes demonstrated a negative predictive value of $100 \%$ for the diagnosis of gluten enteropathy [34].

It is essential to have reliable laboratory techniques for serological screening, because the pediatric gastroenterologists still find the typical form of gluten enteropathy in association with chronic diarrhea a common condition [35].

\section{Conclusions}

According to the high prevalence obtained in this study (6.7 \% and $6.4 \%$ respectively), JIA and AIH are good parameters for stratification of asymptomatic cases in order to perform CD serologic screening. AIH and gluten enteropathy share more selected combinations of genes coding for class II HLA compared to JIA and gluten enteropathy. Considering the first line test HLA typing in asymptomatic at risk children may be beneficial. The absence of DQ2 or DQ8 haplotypes will make $\mathrm{CD}$ diagnosis unlikely and no further tests will be required.

\section{References}

1. CHOU, R., BOUGATSOS, C., BLAZINA, I., MACKEY, K., GRUSING, S., SELPH, S., Screening for Celiac Disease: Evidence Report and Systematic Review for the US Preventive Services Task Force, JAMA, 317(12), 2017, 1258-1268.

2. KELLY, C.P., BAI, J.C., LIU, E., LEFFLER, D.A., Advances in diagnosis and management of celiac disease, Gastroenterology, 148(6), 2015, 1175-1186.

3. FASANO, A., CATASSI, C., Current approaches to diagnosis and treatment of celiac disease: an evolving spectrum, Gastroenterology, 120(3), 2001, 636-651.

4. AlMAllOUHI, E., KING, K.S., PATEL, B., WI, C., JUHN, Y.J., MURRAY, J.A., et al. Increasing Incidence and Altered Presentation in a Population-Based Study of Pediatric Celiac Disease in North America, J. Pediatr. Gastroenterol. Nutr., 65(4), 2017, 432-437.

5. ROSÉN, A., SANDSTRÖM, O., CARLSSON, A., HÖGBERG, L., OLÉN, O., STENLUND, H., et al. Usefulness of symptoms to screen for celiac disease, Pediatrics, 133(2), 2014, 211-218.

6. CATASSI, C., KRYSZAK, D., BHATTI, B., STURGEON, C., HELZLSOUER, K., CLIPP, S.L., et al., Natural history of celiac disease autoimmunity in a USA cohort followed since 1974, Ann. Med., 42(7), 2010, 530-538.

7. SRIVASTAVA, A., CHATURVEDI, S., MATHIAS, A., SHUKLA, U., YACHHA, S.K., DABADGHAO, P., et al., Prevalence of celiac disease in Indian children with type 1 diabetes, Indian J. Gastroenterol., 35(5), 2016, 372-378.

8. FREEMAN, H.J., Endocrine manifestations in celiac disease, World J. Gastroenterol., 14(38), 2016, 8472-8479.

9. KONING, F., Recent insight in the pathophysiology of coeliac disease: relevance to rheumatoid arthritis, Clin. Exp. Reumatol., 33(4 Suppl 92), 2015, 8-10.

10. NAJAFI, M., SADJADEI, N., EFTEKHARI, K., KHODADAD, A., MOTAMED, F., FALLAHI, G.H., et al., Prevalence of Celiac Disease in Children with Autoimmune Hepatitis and vice versa, Iran J. Pediatr., 24(6), 2014, 723-728. 
11. KHAMMASSI, N., MOHSEN, D., KORT, Y., ABDELHEDI, H., CHERIF, O., Association Gougerot Sjogren syndrome and celiac disease, Pan. Afr. Med. J. 15, 2015, 22-33.

12. PALlAV, K., XU, H., LEFFLER, D.A., KABBANI, T., KELLY, C.P., Immunoglobulin A deficiency in Celiac Disease in the United States, J. Gastroenterol. Hepatol., 31(1), 2016, 133-137.

13. COLLIN, P., SALMI, T.T., HERVONEN, K., KAUKINEN, K., REUNALA, T., Dermatitis herpetiformis: a cutaneous manifestation of coeliac disease, Ann. Med., 49(1), 2017, p.23-31.

14. PETTY, R.E., SOUTHWOOD, T.R., MANNERS, P., BAUM, J., GLASS, D.N., GOLDENBERG, J., et al., International League of Associations for Rheumatology. International League of Associations for Rheumatology classification of juvenile idiopathic arthritis, J. Rheumatol., 31, 2004, 390-392.

15. EBBESON, R.L., SCHREIBER, R.A., Diagnosing autoimmune hepatitis in children: is the International Autoimmune Hepatitis Group scoring system useful?, Clin. Gastroenterol. Hepatol., 2(10), 2004, 935-940.

16. ANSGAR, W., CHAZOUIllères, O., DALEKOS, G., DRENTH, J., HENEGHAN, M., HOFER, H., et al., EASL Clinical Practice Guidelines: Autoimmune hepatitis., J. Hepatol., 63(4), 2015, 971-1004.

17. OBERHUBER, G., GRANDITSCH, G., VOGELSANG, H., The histopathology of coeliac disease: time for a standardized report scheme for pathologists, Eur. J. Gastroenterol. Hepatol., 11(10), 1999, 1185-1194.

18. LEPORE, L., MARTELOSSI, S., PENNESI, M., FALCINI, F., ERMINI, M.L., FERRARI, R., et al., Prevalence of celiac disease in patients with juvenile chronic arthritis, J. Pediatr., 129, 1996, 311313.

19. AL-MAYOUF, S.M., AL-MEHAIDIB, A.I., ALKAFF, M.A., The significance of elevated serologic markers of celiac disease in children with juvenile rheumatoid arthritis, Saudi $J$. Gastroenterol., 9, 2003, 75-78.

20. ALPIGIANI, M.G., HAUPT, R., PARODI, S., CALCAGNO, A., POGGI, E., LORINI, R., Coeliac disease in 108 patients with juvenile idiopathic arthritis: a 13-year follow-up study, Clin. Exp. Rheumatol., 26, 2008, 162.

21. POHJANKOSKI, H., KAUTIAINEN, H., KOTANIEMI, K., KORPPI, M., SAVOLAINEN, A., Autoimmune diseases in children with juvenile idiopathic arthritis, Scand. J. Rheumatol., 39, 2010, 435-436.

22. STAGI, S., GIANI, T., SIMONINI, G., FALCINI, F., Thyroid function, autoimmune thyroiditis and coeliac disease in juvenile connective tissue diseases, Rheumatology (Oxford), 44, 2005, 517-520. 23. MICHELIN, C.M., AIKAWA, N.E., DINIZ, J.C., JESUS, A.A., LING KODA, Y.K., SILVA, C.A., Association of systemic-onset juvenile idiopathic arthritis and celiac disease - a case report, Acta. Reumatol. Port., 36.,2011, 404-407.

24. GHEITA, T.A., FAWZY, S.M., NOUR EL-DIN, A.M., GOMAA, H.E., Asymptomatic celiac sprue in juvenile rheumatic diseases children, Int. J. Rheum. Dis., 15(2), 2012, 220-226.

25. SKRABL-BAUMGARTNER, A., ALMUTHE, C.H.H., ERWA, W., JAHNEL, J., HLA genotyping as first-line screening tool for coeliac disease in children with juvenile idiopathic arthritis, Arch. Dis. Child., 102(7), 2017, 607-611.

26. DAVISON, S., Coeliac disease and liver dysfunction, Arch. Dis. Child., 87(4), 2002, 293-296.

27. WONG, G.W., HENEGHAN, M.A., Association of Extrahepatic Manifestations with Autoimmune Hepatitis, Dig. Dis., 33(Suppl 2), 2015, 25-35.

28. ALMEIDA, L.M., GANDOLFI, L., PRATESI, R., UENISHI, R.H., et al., Presence of DQ2.2 Associated with DQ2.5 Increases the Risk for Celiac Disease, Autoimmune Dis., 2016; Article ID 5409653, http://dx.doi.org/10.1155/2016/5409653.

29. HUSBY, S., et al., European Society Paediatric Gastroenterology, Hepatology and Nutrition guidelines for diagnosing coeliac disease 2019., J. Ped. Gastroent. Nutr., 2019, Publish Ahead of Print, DOI: 10.1097/MPG.0000000000002497 
30. AGUAYO-PATRÓN, S., BELTRÁN-SAUCEDA, L., CALDERÓN DE LA BARCA, A.M., A population-wide applicable HLA-DQ2 and DQ8 genotyping using DNA from dried blood spots and duplex allele-specific qPCR amplification, Scand. J. Clin. Lab. Invest., 76(7), 2016, 581-587.

31. PANETTA, F., NOBILI, V., SARTORELLI, M.R., PAPA, R.E., FERRETTI, F., ALTERIO, A., et al., Celiac disease in pediatric patients with autoimmune hepatitis: etiology, diagnosis, and management, Pediatric. Drugs., 14(1), 2012, 35-41.

32. HOLLENBACH, J.A., BUGAWAN, T.L., ERLICH, H.A., Juvenile idiopathic arthritis and HLA class I and class II interaction and age of onset effects, Arthritis. Rheum., 62(6), 2010, 1781-1791.

33. SMYTH, D.J., PLAGNOL, V., WALKER, N.M., COOPER, J.D., DOWNES, K., YANG, J.H., et al., Shared and distinct genetic variants in type 1 diabetes and celiac disease, N. Engl. J. Med., 359(26), 2008, 2767-2777.

34. MURCH, S., Recent Advances in Celiac Disease, Indian J. Pediatr., 83(12-13), 2016, p.14281435 .

35. BELEI, O.A., HEREDEA, E.R., BOERIU, E., MARCOVICI, T.M., CERBU, S., MĂRGINEAN, O., IACOB, E.R., IACOB, D., MOTOC, A.G.M., BOIA, E.S., Verner-Morrison syndrome. Literature review, Rom. J. Morphol. Embryol., 58(2), 2017, 371-376.

Manuscript received: 28.10 .2019 